\section{Bronchiolitis obliterans syndrome leads to a functional deterioration of the acinus post lung transplant}

\section{ABSTRACT}

Bronchiolitis obliterans syndrome (BOS) limits long-term survival of lung transplant recipients, and airflow obstruction in these patients likely originates in the small airways. 61 double lung transplant recipients performed multiple breath nitrogen washouts to obtain indices of acinar and conductive ventilation heterogeneity $\left(S_{\text {acin }}, S_{\text {cond }}\right)$. There was a significant association of BOS status with $S_{\text {acin }}$ (Kruskal-Wallis; $p<0.001$ ) but not with $S_{\text {cond }}(p=0.1)$. These results demonstrate that it is the structural alteration of the terminal bronchioles, generating ventilation heterogeneity at the level of the diffusion front, and not the bronchioles located more proximally, that is driving the airflow obstruction that determines BOS status.

Bronchiolitis obliterans syndrome (BOS) in a lung transplant recipient is a form of chronic lung allograft rejection, currently defined by a decline in forced expiratory volume in 1 second $\left(\mathrm{FEV}_{1}\right)$ of more than $20 \%$ in the presence of airflow obstruction $\left(\mathrm{FEV}_{1} / \mathrm{FVC}<70 \%\right) .{ }^{1}$ Despite histological evidence of peripheral airways involvement in BOS, physiological measurements of BOS are relatively sparse, with tests of ventilation distribution showing promise for early detection. ${ }^{2}$ As spirometry is relatively insensitive and certainly non-specific to changes within the small airways, pathological changes associated with BOS can be better linked to anatomical structures by a dedicated test of ventilation heterogeneity. ${ }^{3}$ The aim of this study was to determine the effect of BOS stage on ventilation heterogeneity at the level of the terminal bronchioles versus that generated more proximally.

\section{METHODS}

\section{Subject recruitment}

Sixty-one bilateral lung transplant recipients (40 male and 21 female) with varying degrees of BOS were recruited for the study.

\section{Multiple breath nitrogen washout (MBNW)}

MBNW provides indices that can separate gas mixing in the airways at the level of the diffusion front $\left(\mathrm{S}_{\mathrm{acin}}\right)$-likely to be located around the acinar entrance-and that generated more proximally $\left(\mathrm{S}_{\text {cond }}\right)^{3}$; an increase in either $S_{\text {acin }}$ or $S_{\text {cond }}$ reflects an increased degree of ventilation heterogeneity, that is, a deterioration in lung function.

\section{RESULTS}

Individual values of $S_{\text {acin }}$ and $S_{\text {cond }}$ against BOS stage can be appreciated from figure 1 . All subjects with a BOS stage $\geq 1$ showed a significantly greater $S_{\text {acin }}$ versus $B O S=0$ subjects, and $\mathrm{BOS}=3$ patients showed significantly greater $S_{\text {acin }}$ than $B O S=1$ or $\mathrm{BOS}=2$ patients (figure $1 \mathrm{~A}$ ). There was no significant dependence of $\mathrm{S}_{\text {cond }}$ on BOS status (figure $1 \mathrm{~B}$ ). There was a strong correlation of $\mathrm{FEV}_{1} / \mathrm{FVC}$ with $\mathrm{S}_{\text {acin }}$ (Spearman rho $=-0.72 ; \mathrm{p}<0.001$ ) but not with $S_{\text {cond }}(p=0.097)$.

\section{DISCUSSION}

We have identified a functional correlate of airway obstruction in patients who fit the strict definition of $\mathrm{BOS}^{1}$ by observing increased acinar ventilation heterogeneity $\left(\mathrm{S}_{\text {acin }}\right)$ with BOS stage. Based on mathematical modelling, $S_{\text {acin }}$ is assumed to be generated around the terminal bronchioles, ${ }^{3}$ hence our functional findings are in agreement with recent observations from micro CT on explanted lungs obtained from six patients with BOS undergoing retransplantation. ${ }^{4}$ In this preliminary study published in abstract form, ${ }^{4}$ obliterating lesions are reported in the airways immediately proximal to the terminal bronchioles, that is, preterminal bronchioles, of patients with BOS. Beyond these, a normal airway structure leading into the alveolated zone was observed. One could speculate that excessive narrowing of preterminal bronchioles airways shifts the diffusion front, which is the basis of $S_{\text {acin }}$ measurement. Coincidently, recent mathematical modelling work published in abstract form by Murphy et $a l^{5}$ indicated that even with up to $50 \%$ airway narrowing in the preterminal bronchioles the diffusion front hardly moved (by $\sim 1$ generation proximally). This provides compelling support to the fact that the measured $\mathrm{S}_{\text {acin }}$ increases with increasing BOS stage are indeed the result of worsening ventilation heterogeneity generated at the level of the acinar entrance.
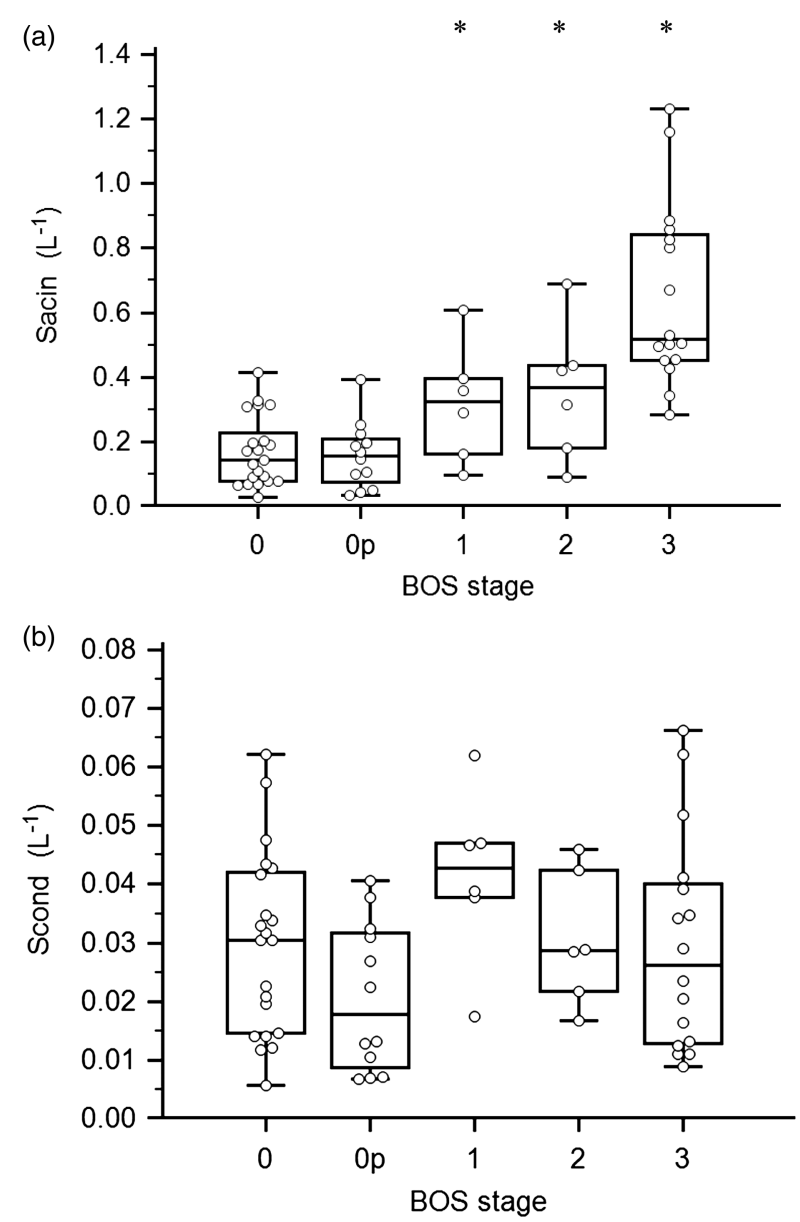

Figure 1 Box-and-whisker plots of $S_{\text {acin }}(A)$ or $S_{\text {cond }}(B)$ versus bronchiolitis obliterans syndrome (BOS) status; asterisks indicate significant changes versus $B O S=0$ subjects. In addition, $S_{\text {acin }}$ in patients with $B O S=1$ or $B O S=2$ was not different from each other but significantly different from $\mathrm{S}_{\text {acin }}$ observed in $\mathrm{BOS}=0$ and $\mathrm{BOS}=3$ patients. 


\section{CONCLUSION}

In a cross-sectional study, the reduction in $\mathrm{FEV}_{1}$ seen with BOS is associated with functional changes generated around the acinar entrance.

Bruce R Thompson, ${ }^{1,3}$ Yvonne M Hodgson, ${ }^{3}$ Tom Kotsimbos, ${ }^{1}$ Pam Liakakos, ${ }^{1}$ Matthew J Ellis, ${ }^{1}$ Gregory I Snell, ${ }^{1}$ Sylvia Verbanck ${ }^{2}$

${ }^{1}$ Allergy, Immunology, and Respiratory Medicine, Alfred Hospital, Melbourne, Australia

${ }^{2}$ Respiratory Division, University Hospital UZ Brussel, Brussels, Belgium

${ }^{3}$ Department of Medicine, Monash University, Melbourne, Australia

Correspondence to Professor Bruce Thompson; b.thompson@alfred.org.au

Contributors BRT and SV were involved in the conception, hypotheses, design of the study, interpretation of such information, writing the article and revision prior to submission. YMH, MJE and PL were involved in data acquisition, analysis of results and writing of the article. GIS and TK were involved in subject recruitment, interpretation of results, writing of the article and revision prior to submission.

Funding BRT would like to acknowledge the financial support of the National Health and Medical Research Council of Australia (grants 486101 and 491103).

Competing interests None.

Ethics approval The Alfred Hospital Research and Ethics Committee.

Provenance and peer review Not commissioned; internally peer reviewed.

To cite Thompson BR, Hodgson YM, Kotsimbos T, et al. Thorax Published Online First: [please include Day Month Year] doi:10.1136/thoraxjnl-2013-204671

Received 13 October 2013

Accepted 17 October 2013

Published Online First 8 November 2013
Thorax 2014:69:487-488.

doi:10.1136/thoraxjnl-2013-204671

\section{REFERENCES}

1 Estenne M, Maurer J, Boehler A, et al. Bronchiolitis obliterans syndrome 2001: an update of the diagnostic criteria. J Heart Lung Trans 2002;21:297-310.

2 Estenne M, Van Muylem A, Knoop C, et al. Detection of obliterative bronchiolitis after lung transplantation by indexes of ventilation. Am J Respir Crit Care Med 2000;162:1047-51.

3 Verbanck S, Paiva M. Gas mixing in the airways and air spaces. Compr Physiol 2011;1:809-34.

4 Verleden SE, Vasilescu DM, Willems S, et al. The site and nature of airway obstruction following lung transplantation [abstract]. Belgian Transplant Society 2013:P7.

5 Murphy K, Thompson BR, Tawhai M. Assessing the effect of anatomical structure and gravity on diffusion front location [abstract]. Am J Respir Crit Care Med 2013;187:A1960. 